\title{
Experimental diabetes exacerbates skin transplant rejection in rats $^{1}$
}

\author{
Flávio Pola dos Reis ${ }^{\mathrm{I}}$, Angelo Sementilli ${ }^{\mathrm{II}}$, Antonio Ricardo de Toledo Gagliardi ${ }^{\mathrm{II}}$
}

${ }^{\mathrm{I}}$ Graduate student, Lusiada University Center, Santos-SP, Brazil. Acquisition and interpretation of data, technical procedures, manuscript writing. IIPhD, Chairman and Head, Department of Pathology, Santos Metropolitan University (UNIMES) and Full Professor, Department of Pathology, Lusiada University Center, Santos-SP, Brazil. Macroscopic and histopathological examination, interpretation of data.

IIIPhD, Full Professor, Department of Physiology and Biophysics, Lusiada University Center, Santos-SP, Brazil. Conception of the study, manuscript writing, critical revision.

\section{ABSTRACT}

PURPOSE: To investigate the effect of chronic experimental diabetes on skin allografts in rats as a simple model that could clarify some basic aspects and mechanisms involved in transplant rejection in diabetes compared to normal animals.

METHODS: Skin grafting was performed with fragments of tail skin from sex matched non diabetic Wistar rats engrafted onto the thoracic area of diabetic and non diabetic recipients. Grafts were scored for rejection every other day and were removed on day 14 . Skin grafts were graded according to the following itens: no rejection; or rejection including: acute, chronic and humoral and/or cellular rejection. Statistical analysis was performed using JMP 5.1 software with ANOVA test. Diabetes was induced with IV injection of alloxan $40 \mathrm{mg} / \mathrm{kg}$.

RESULTS: Inflammatory vascular infiltrate compromising the endothelium with areas of fibrinoid necrosis and thrombosis characteristics of acute humoral rejection and subendothelial lymphocyte infiltrate typical of acute cellular rejection were significantly $(\mathrm{p}<0.003)$ higher in diabetic than in non diabetic recipients as the inflammatory infiltrate in the epidermis $(\mathrm{p}<0.002)$.

CONCLUSION: Skin transplant acute rejection from chronic alloxan diabetic rats to normal tissue was significantly more intense than the acute rejection between normal rats.

Key words: Transplantation. Skin. Diabetes Mellitus, Experimental. Graft Rejection. Rats, Wistar. 


\section{Introduction}

Diabetes mellitus (DM) is an important cause of mortality and morbidity worldwide, through both direct clinical complications and the high risk for cardiovascular and kidney diseases. Systematic analysis ${ }^{1}$ showed that hyperglycaemia and diabetes are a rising global hazard, considering that the number of adults with diabetes more than doubled over nearly three decades.

The proportion of patients with diabetes mellitus that progresses to End Stage Renal Disease is increasing. The increased prevalence of diabetes mellitus is estimated to account for $28 \%$ incidence of renal replacement therapy in general $^{2}$ and diabetes mellitus is the most common cause of end-stage renal disease in the United States, accounting for up to $46 \%$ of patients on renal replacement therapy each year ${ }^{3}$.

Following kidney transplantation, the prevalence of rejection in patients with diabetes mellitus is slightly but not significantly higher than in non-diabetic subjects ${ }^{4}$. It has been shown that the five year graft survival was $74 \%$ for nondiabetics, $72 \%$ for those with type 1 diabetes and $47 \%$ for those with type 2 diabetes. Ten year graft survival was $65 \%$ for non-diabetics and $59 \%$ for those with type 1 diabetes. Forty-four percent of the non-diabetic recipients developed acute rejection episodes, as did $50 \%$ of recipients with type 1 and $57.1 \%$ of recipients with type 2 diabetes 5 .

Clinical and experimental data concerning acute kidney transplantation rejection in diabetes mellitus is scarce ${ }^{4}$.

We investigated the effect of chronic experimental diabetes on skin allografts in rats as a simple model that could clarify some basic aspects and mechanisms involved in acute transplant rejection in diabetes.

\section{Methods}

Wistar rats of both sex, were kept at the animal facility in standardized conditions of temperature and light/dark cycles for ten days for adaptation prior to any procedure. Animals from outbred stocks were used as donors and recipients, more similar to the clinical conditions. The experimental protocol was approved by the Institutional Ethical Committee on Animal Experiments.

Rats were rendered diabetic by treatment with alloxan (40 mg/kg of body weight; Sigma Chemical Co., St. Louis, Missouri, USA) dissolved in $0.2 \mathrm{ml} \mathrm{NaCl}(0.15 \mathrm{M})$ and immediately administered intravenously to the anesthetized rat. A glucose $10 \%$ solution was offered as drinking water to offset transient hypoglycemia developing after alloxan treatment. Rats were considered diabetic when fasting plasma glucose concentrations were greater than $250 \mathrm{mg} / \mathrm{dl}$ because this dose of alloxan causes total destruction of pancreatic $\beta$ cells. Age- and weight-matched rats were used as nondiabetic control animals.

Animals were assigned by chance to two groups, in the experimental group $n=10(\mathrm{G} 1)$ diabetic animals received skin graft from nondiabetic rats and in the control group $n=14(G 2)$ nondiabetic rats received skin graft from nondiabetic rats.

Tail-to-dorsum skin transplants were performed. Briefly, animals were anesthetized with eter, the dorsum was washed and a wound was created to be filled with the transplanted tail skin. The graft was gently placed on the wound surface. The tail grafts, a skin fragment of approximately $6.25 \mathrm{~cm}^{2}$ was used. Grafting was fixed with nylon 3.0 stitches. On day fourteen, animals were sacrificed, graft removed with a $5 \mathrm{~mm}$ of animal skin edge and collected in $10 \%$ formalin.

Histology was performed on tissue sections $(4 \mu \mathrm{m})$ after paraffin-embedding and staining with haematoxylin-eosin (HE) using standard protocols, at least two sections and four fragments were analyzed for it sample. Grafts were scored blindly by an experienced pathologist. The skin grafts were classified as displaying no rejection (no or minimal inflammatory cells infiltrating the dermis, normal appearance of hair follicles); acute humoral rejection (presence of areas of fibrinoid necrosis and thrombosis); acute cellular rejection (inflammatory lymphocytic infiltration with intense aggression to the epidermis, to the hair follicles and vessel walls) (Figure 1). Acute cellular rejection was considered grade I (infiltrate reaching vessel intima), grade II (infiltrate reaching muscle sheath) and grade III (transmural infiltrate) (Figure 2). Chronic rejection was characterized by extensive fibrosis, collagen deposits within the dermis, and discrete leucocyte infiltration. Immunohistochemistry was performed to identify cellular rejection: lymphocytes T (CD3), lymphocytes B (CD20) and macrophage (CD68) (Figure 3).

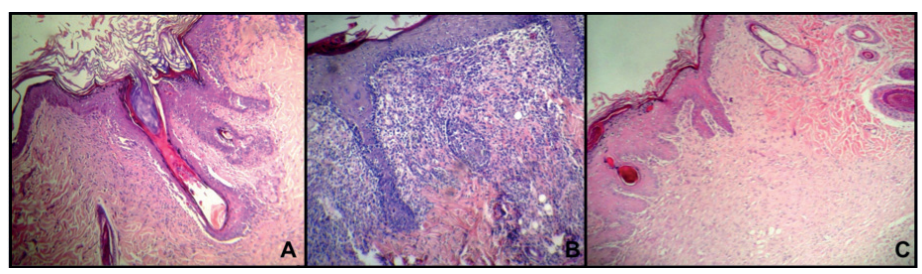

FIGURE 1 - Photomicrograph (HE) showing in section A, acute cellular rejection grade $\mathrm{I}$ in hair follicle $(100 \mathrm{x})$. Section $\mathrm{B}$, acute cellular rejection grade II in hair follicle (100x). Section C, transition between graft and self skin, showing signs of chronification (40x). 


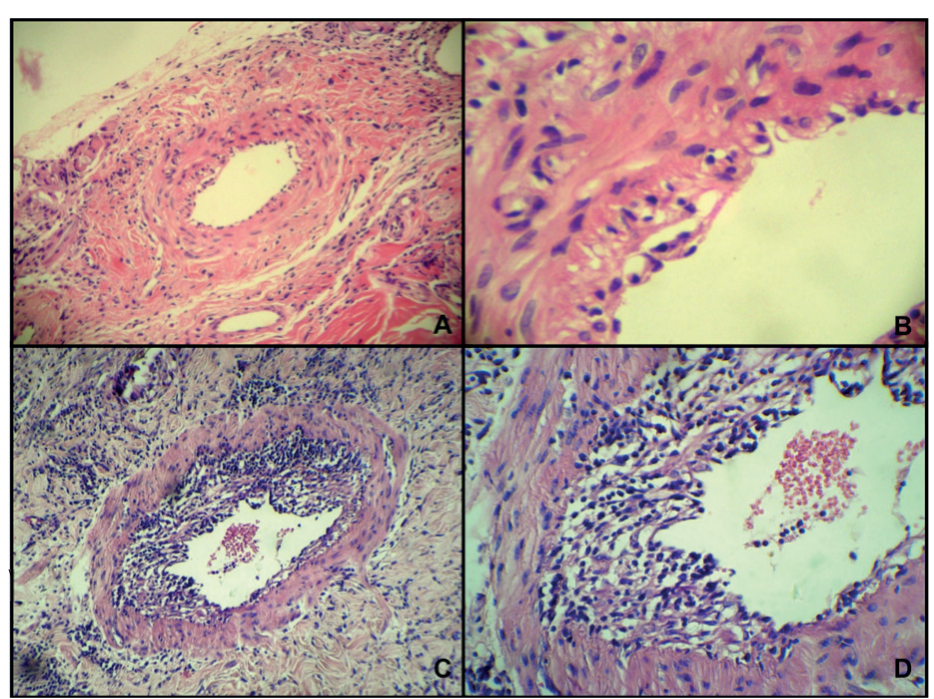

FIGURE 2 - A. Endothelial acute cellular rejection (100x). B. Subendothelial lymphocytic infiltrate $(400 x)$. C. Lymphocyte infiltrate in muscle sheath (100x) and D (400x-H\&E).

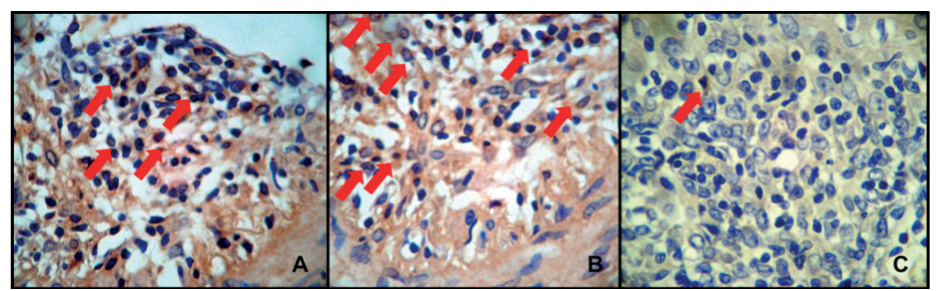

FIGURE 3 - Photomicrograph showing acute cellular rejection grade II. Section A, cells expressing CD68. Section $\mathbf{B}$, cells expressing CD3. Section $\mathbf{C}$, cells expressing CD20. Arrows indicate positive cells.

Statistical analysis was performed with ANOVA (parametric variables) and $\mathrm{x}^{2}$ (categorical variables), data are reported as mean $\pm \mathrm{SD}$. P values less than 0.05 was considered statistically significant.]

\section{Results}

Average weight for the diabetic (G1) and control (G2) groups was respectively $259.3 \mathrm{~g}$ (71) and $360.8 \mathrm{~g}$ (105) $\mathrm{p}=0.01$. Blood glucose was $414.2 \mathrm{mg} / \mathrm{dL}$ (94.1) and $111.7 \mathrm{mg} / \mathrm{dL}$ (16.4) $\mathrm{p}<0.0001$.

Histopathological analysis of grafts of $\mathrm{G} 1$ and $\mathrm{G} 2$ is shown in Table 1. Epidermal inflammatory infiltrate in G1 was $90 \%$ neutrophilic and $10 \%$ mix with lymphocyte predominance and presence of eosinophils, in G2 the infiltrate was 100\% neutrophilic $(\mathrm{p}=0.22)$. Dermal inflammatory infiltrate in G1 was mix with $40 \%$ lymphocytic and $60 \%$ mononuclear. Dermal infiltrate in G2 was mix with $28.5 \%$ lymphocytic and $71.5 \%$ mononuclear $(\mathrm{p}=0.55)$.
TABLE 1 - Histopathology of graft tissue.

\begin{tabular}{|c|c|c|c|}
\hline & $\begin{array}{c}\text { Diabetic - } \\
\quad \text { G1 } \\
\mathrm{n}=10(\mathrm{SD})\end{array}$ & $\begin{array}{c}\text { Control - } \\
\text { G2 } \\
\mathrm{n}=14(\mathrm{SD})\end{array}$ & $\underset{\text { value }}{p}$ \\
\hline Edema & $2.00(0.66)$ & $1.64(0.63)$ & 0.19 \\
\hline Ulceration & $1.50(0.84)$ & $1.07(0.61)$ & 0.16 \\
\hline $\begin{array}{l}\text { Ischemic Necrosis of Epi- } \\
\text { dermis }\end{array}$ & $1.50(0.84)$ & $1.71(0.91)$ & 0.56 \\
\hline Fibrosis & $1.80(0.63)$ & $1.64(0.63)$ & 0.55 \\
\hline Foreing Body Granuloma & $1.40(0.51)$ & $1.35(0.49)$ & 0.83 \\
\hline Neovascularization & $1.90(0.73)$ & $1.57(0.51)$ & 0.21 \\
\hline $\begin{array}{l}\text { Inflammatory infiltrate in the } \\
\text { epidermis }\end{array}$ & $1.90(0.56)$ & $1.21(0.42)$ & 0.002 \\
\hline $\begin{array}{l}\text { Inflammatory infiltrate in the } \\
\text { dermis }\end{array}$ & $1.90(0.56)$ & $1.64(0.49)$ & 0.25 \\
\hline Necrosis of Hair Follicle & $1.70(0.67)$ & $1.71(0.61)$ & 0.95 \\
\hline $\begin{array}{l}\text { Lymphocyte Aggression in } \\
\text { Hair Follicle }\end{array}$ & $0.50(0.84)$ & $0.57(0.75)$ & 0.83 \\
\hline $\begin{array}{l}\text { Vascular Inflammatory } \\
\text { infiltrate }\end{array}$ & $1.20(0.42)$ & $0.42(0.64)$ & 0.003 \\
\hline
\end{tabular}

Note: Values represent the mean of the intensity of histopathologic findings classified from $0-3$. Statistical analysis was done with ANOVA, $\mathrm{p}<0.05$.

Diabetic group showed mainly cellular and/or humoral acute rejection with few animals in the initial phase of chronicity. Immunohistochemistry of the infiltrate showed: $70 \%$ of $\mathrm{T}$ lymphocytes, $30 \%$ of macrophages, and negative for B lymphocytes. Control group was characterized by low intensity acute cellular rejection with well established chronicity $(p=0.13)$.

\section{Discussion}

Medawar et al. ${ }^{6}$, during the Second World War historically studied skin transplantation in large scale in severely burnt soldiers, showing the results for auto versus allograft. The same group of investigators showed a few years later that it was possible to induce immune acceptance of skin grafts in mice, in a state of immune tolerance ${ }^{7}$, establishing the well known, Transplantation Law. This experimental model is still used as the gold standard in studies of transplant immunology including reconstructive sur- 
gery. After over six decades, however, the precise mechanism of skin allograft rejection remains still ill-defined ${ }^{8}$.

The major complication with this technique is the partial or complete ischemic necrosis of the flap, a process that has been attributed to an inadequate blood supply as a consequence of insufficient vascularization, vasospasm, impaired venous return and thrombosis ${ }^{9}$ that is enhanced in diabetes.

Our most significant finding was related to the vascular inflammatory infiltrate that was prominent in the diabetic group compared to controls characterizing more intense acute rejection, as the ischemic necrosis of the epidermis typical of the inflammatory process. Futhermore, diabetic animals didn't show any signs of chronification. Control animals on the other hand presented mild acute cellular rejection and evident chronification. Both groups exhibited lymphocytic infiltration of the hair follicles, neovascularization, ulceration and edema. We recognize that the use of outbred animals is a weakness in our data analysis but we must take in consideration that in the clinical scenario of human transplantation in most of the cases there is no perfect matching between donor and recipient. Alloxan is widely used to induce experimental diabetes and the mechanism of its action has been intensively investigated and now is well known. The cytotoxicity to the beta cell is mediated by reactive oxygen species and does not interfere with the animal immune system differently from streptozotocin ${ }^{10}$. Alloxan by itself probably did not have any effect on the immune response of our experimental animals. To our knowledge, this is the first experimental evidence of enhanced transplant acute rejection in diabetic animals against normal tissue.

Pathophysiological mechanisms involved in the exacerbation of transplant rejection in diabetic animals could be related to the increased chronic oxidative stress of the hyperglycemic state, microvascular, endothelial, lymphocyte and mononuclear dysfunctions.

\section{Conclusion}

Skin transplant acute rejection from chronic alloxan diabetic rats to normal donors was significantly more intense than the skin transplant acute rejection between normal animals.

\section{References}

1. Danaei G, Finucane MM, Lu Y, Singh GM, Cowan MJ, Paciorek CJ, Lin JK, Farzadfar F, Khang YH, Stevens GA, Rao M, Ali MK, Riley LM, Robinson CA, Ezzati M. National, regional, and global trends in fasting plasma glucose and diabetes prevalence since 1980: systematic analysis of health examination surveys and epidemiological studies with 370 country-years and 2.7 million participants. Lancet. 2011;378(9785):31-40.

2. Schroijen MA, Dekkers OM, Grootendorst DC, Noordzij M, Romijn JA, Krediet RT, Boeschoten EW, Dekker FW. Survival in dialysis patients is not different between patients with diabetes as primary renal disease and patients with diabetes as a co-morbid condition. BMC Nephrology. 2011;12:69.

3. McFarlane SI, McCullough PA, Sowers JR, Soe K, Chen SC, Li S, Vassalotti JA, Stevens LA, Salifu MO, Kurella Tamura M, Bomback AS, Norris KC, Collins AJ, Bakris GL, Whaley-Connell AT. Comparison of the CKD Epidemiology Collaboration (CKD-EPI) and Modification of Diet in Renal Disease (MDRD) study equations: prevalence of and risk factors for diabetes mellitus in CKD in the Kidney Early Evaluation Program (KEEP). Am J Kidney Dis. 2011;57(3 Suppl 2):S24-31.

4. Schiel R, Heinrich S, Steiner T, Ott U, Stein G. Long-term prognosis of patients after kidney transplantation: a comparison of those with or without diabetes mellitus. Nephrol Dial Transplant. 2005;20(3):611-7.

5. Revanur VK, Jardine AG, Kingsmore DB, Jaques BC, Hamilton $\mathrm{DH}$, Jindal RM. Influence of diabetes mellitus on patient and graft survival in recipients of kidney transplantation. Clin Transplant. 2001;15(2):89-94.

6. Gibson T, Medawar PB. The fate of skin homografts in man. J Anat. 1943;77:299-310.

7. Billingham RE, Brent L, Medawar PB. Actively acquired tolerance to foreign cells. Nature. 1953;172(4379):603-6.

8. Horner BM, Randolph MA, Huang CA, Butler PEM. Skin tolerance: in search of the Holy Grail. Transpl Int. 2008;21(2):101-12.

9. Schurmann C, Seitz O, Sader R, Pfeilschifter J, Goren I, Frank S. Role of wound macrophages in skin flap loss or survival in an experimental diabetes model. Br J Surg. 2010;97(9):1437-51.

10. Szkudelski T. The mechanism of alloxan and streptozotocin action in B cells of the rat pancreas. Physiol Res. 2001;50:537-46.

\section{Correspondence:}

Antonio Ricardo de Toledo Gagliardi

Rua Padre Visconte, 10/81

11040-150 Santos - SP Brasil

antoniogagliardi@ig.com.br

Received: January 14, 2013

Review: March 18, 2013

Accepted: April 16, 2013

Conflict of interest: none

Financial source: none

${ }^{1}$ Research performed at Laboratory of Physiology and Biophysics, School of Medicine, Lusiada University Center, Santos-SP, Brazil. 